\title{
ESCUTA PROTEGIDA - LEI 13.431/17 E A APLICABILIDADE DO DEPOIMENTO ESPECIAL
}

\section{LISTENING PROTECTED - LAW 13.431 / 17 AND THE APPLICABILITY OF SPECIAL STATEMENT}

REJANE HARTMANN

Acadêmica do curso de Direito - Faculdade do Litoral do Paraná - ISEPE. Guaratuba - PR. E-mail: rejanehb@tjsc.jus.br

FOED SMAKA SALIBA JUNIOR Professor Orientador - Faculdade do Litoral do Paraná - ISEPE. Guaratuba - PR. Email: isepe@smaka.adv.br

\section{RESUMO}

No sistema de justiça brasileiro o testemunho de crianças e adolescentes, quando vítimas ou testemunhas de violência, para aferição de prova, passavam pelo mesmo sistema de inquirição pelo qual passam os adultos, não havendo pelo ordenamento pátrio a devida consideração quanto à sua condição de pessoa em desenvolvimento. Sem uma legislação específica sobre o tema que garantisse seus direitos fundamentais esta forma de inquirição os expunha à vitimização secundária resultando em violência institucional. Desde a Constituição da República Federativa do Brasil de 1988 as crianças e a adolescentes gozam do princípio da dignidade da pessoa humana conforme se confere em seu Art. 1ํㅜㄹ inciso III; posteriormente também disposto no Art. 3. do Estatuto da Criança e do Adolescente - Lei 8069/90. O art. 227 da CF inaugurou a Doutrina da Proteção Integral dispondo sobre o dever de todos em 


\section{Personalidade Acadêmica Homenageada:}

Augustus B. Cochran III (Agnes Scott College)

assegurar-lhes com absoluta prioridade o combate à violações e garantindo seus direitos fundamentais; princípios estes repetidos no art. 4ํㅜ do ECA. A Convenção Internacional sobre os Direitos da Criança, do qual o Brasil passou a ser signatário através do Decreto n. 999.710/1990, em seu Art. 12 conferiu-Ihes o direito de serem ouvidos. Buscando o estabelecimento destas garantias no sistema de justiça o

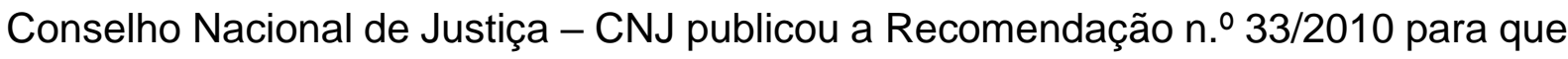
todos os tribunais criassem serviços especializados para escuta de crianças e adolescentes vítimas ou testemunhas de violência nos processos judiciais. Batizada de Escuta Protegida a lei 13.431 foi aprovada em 2017, gênero de duas espécies de escuta: escuta especializada e depoimento especial, estabelece o sistema especializado de garantia de direitos da criança e do adolescente vítima ou testemunha de violência possuindo função de assegurar-lhes direitos e proteção através da regra da oitiva única e obter uma prova com melhor qualidade. O depoimento especial à ser realizado em ambiente separado da sala de audiências através de sistema de depoimento vídeo gravado, com participação de profissional capacitado em técnicas de entrevista investigativa, possui objetivo de obtenção de informações fidedignas baseadas na recuperação de memória e assegurar-lhes o direito de serem ouvidos nos processos judiciais que se encontram diretamente envolvidos ou de ficar em silêncio, diminuindo-se o tempo entre a denúncia e a escuta. Após a publicação da Lei que cria a obrigatoriedade do depoimento especial, o Tribunal de Justiça de Santa Catarina através da Resolução Conjunta GP/CGJ n. 8 de 24 de setembro de 2018, sob a Coordenadoria Estadual da Infância e da Juventude -CEIJ, passou a implantar nas Comarcas de Santa Catarina "O Depoimento Especial". Diante desta nova sistemática, com foco no princípio do melhor interesse da criança e do adolescente e protocolo disposto na Lei 13.431/17, surgiu o interesse em conhecer a prática do depoimento especial das crianças e adolescentes enquanto vítimas ou testemunhas de violência elegendo-se para pesquisa as Comarcas de Itapoá, Garuva e Joinville, as quais compõe o Litoral Norte de Santa Catarina e que estão mais próximas geograficamente da Instituição de Ensino ISEPE. Os dados obtidos, através de pesquisa bibliográfica, entrevista estruturada e visita in locu, destinam-se à elaboração de Artigo Científico como trabalho de conclusão do curso 
Personalidade Acadêmica Homenageada:

Augustus B. Cochran III (Agnes Scott College)

de Direito na Faculdade ISEPE e a ser apresentado à comunidade acadêmica possibilitando o conhecimento da parte prática do depoimento especial. Preliminarmente através das observações e pesquisas já realizadas, embora não conclusivas, foi possível obter-se como resultado a adequada aplicação do protocolo estabelecido na Lei, buscando as Comarcas à garantia dos direitos das crianças e adolescentes enquanto vítimas ou testemunhas de violências.

PALAVRAS-CHAVE: Criança e Adolescente; Violência Institucional; Escuta Protegida.

\section{REFERÊNCIAS}

ASSIS, Simone G. de. Crianças e adolescentes violentados: passado, presente e perspectivas para o futuro. Artigo publicado no Cad. Saúde Pública, Rio de Janeiro, v. 10 (supl. 1), ano 1994. p. 126-134, Disponível em $<$ http://www.scielo.br/pdf/\%0D/csp/v10s1/v10supl1a08> .pdf. Acesso em 09/03/19.

AZAMBUJA, Maria Regina Fay et. al. A Inquirição da criança e do adolescente no âmbito judiciário. IN: Conselho Federal de Psicologia. A Escuta de Crianças e Adolescentes envolvidos em situação de violência e a Rede de Proteção. Brasília: CFP, 2010.

CEZAR José Antônio Daltoé. Projeto Depoimento Sem Dano Direito ao Desenvolvimento Sexual Saudável. AMB - Associação dos Magistrados $\begin{array}{llllll}\text { Brasileiros. } & 2003 ; & \mathrm{Pg} & 7 . & \text { Disponível } & \text { em }\end{array}$ $<$ http://www.amb.com.br/docs/noticias/2008/projeto DSD> .pdf. Acesso em $17 / 03 / 2019$.

CHILDHOOD BRASIL. Atendimento integrado a crianças vítimas ou testemunhas de violência no planejamento plurianual dos municípios e Estados brasileiros 2018-2021: implementando a LEl 13.431/17. São Paulo. 2017. p 21.

COIMBRA José César. Depoimento especial de crianças: um lugar entre proteção e responsabilização? Scielo. Psicologia: Ciência e Profissão. vol.34 no.2 Brasília Apr./June 2014. pg 365. Disponível em <http://www.scielo.br/scielo.php?pid=S1414-

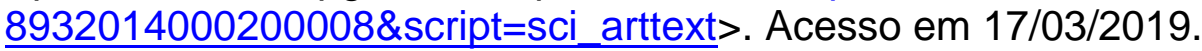


Personalidade Acadêmica Homenageada:

Augustus B. Cochran III (Agnes Scott College)

CONSELHO FEDERAL DE PSICOLOGIA. Protocolo NICHD (national Institute of Child Health and Humn Development), que é uma entrevista investigativa com a finalidade de "avaliação forense de casos com suspeita de abuso sexual infantil". $<$ https://www.site.cfp.org.br/?evento=protocolo-nichd> Protocolo NICHD. Acesso em $10 / 03 / 17$.

BRASIL. Comité dos direitos da criança da ONU. Comentário Geral n. 12 .

. Conselho Nacional de Justiça. Recomendação n. 33, de 23 de novembro de 2010. Recomenda aos Tribunais a criação de serviços especializados para escuta de crianças e adolescente vítimas ou testemunhas de violência nos processos judiciais. Depoimento Especial. Diário da Justiça Eletrônico, 25 de novembro de 2010.

. Conselho Econômico e Social das Nações Unidas - Diretrizes para a justiça em assuntos envolvendo crianças vítimas ou testemunhas de crimes. RESOLUÇÃ̃O N. 20/ ECOSOC. Disponível em $<$ http://www.crianca.mppr.mp.br/arquivos/File/legis/onu/resolucao 202005 ecosoc onu port.> pdf. Acesso em 10/03/2019.

. Conselho Nacional de Justiça - CNJ - Depoimento especial: um aliado no combate à violência contra crianças. Notícias Judiciário, matéria publicada em 05/04/2018 - 14h31. Disponível em <http://www.cnj.jus.br/noticias/judiciario/86448depoimento-especial-um-aliado-no-combate-a-violencia-contra-criancas >. Acesso em 11/03/19.

. Constituição da República Federativa do Brasil de 1988, de 5 de outubro de 1988. Diário Oficial da União, Brasília, 1988.

. Decreto n.. 99.710, de 21 de novembro de 1990. Promulga à Convenção sobre os Direitos da Criança. Diário Oficial da União, 22 de novembro de 1990.

$\begin{array}{ccc}\text { Espectos } & \text { Escuta de crianças e adolescentes em situação de violência sexual - } \\ \text { teóricos } & \text { e } & \text { metodológicos. }\end{array}$ $<$ https://www.childhood.org.br/publicacao/Escuta Crianc\%CC\%A7as Adolescentes> pg 289.

. Lei n.o 8.069, de 13 de julho de 1990. Estatuto da Criança e do Adolescente. Diário Oficial da União, Brasília, 1990.

. Lei n.o 13.431, de 4 de Abril de 2017. Estabelece o sistema de garantia de direitos da criança e do adolescente vítimas ou testemunha de violência e altera a Lei n. 8.069/90, de 13 de julho de 1990 (Estatuto da Criança e do Adolescente). Diário Oficial da União, 5 de abril de 2017.

Ministério dos Direitos Humanos. Secretaria de Direitos Humanos da Presidência da República. Conselho Nacional dos Direitos da Criança e do Adolescente. Comissão Intersetorial de Enfrentamento à Violência Sexual contra 
Personalidade Acadêmica Homenageada:

Augustus B. Cochran III (Agnes Scott College)

Crianças e Adolescentes. Parâmetros de Escuta de Crianças e Adolescentes em Situação de Violência. Brasília, 2017.

n. 0 113/06 do CONANDA. Conselho Nacional dos Direitos da Criança. Resolução Resolução n. ${ }^{112 / 06}$ do CONANDA.

Conselho Nacional dos Direitos da Criança. Conselho Nacional dos Direitos da Criança. Resolução

n. ${ }^{169 / 1} 4$ do CONANDA.

Instituto Alana. Programa Prioridade Absoluta - Entenda a Prioridade. $<$ https://prioridadeabsoluta.org.br/entenda-a-prioridade/>. Acesso em 08/03/19.

LEAL, Fabio Gesser; Klauss Corrêa de Souza; Rafael Giordani Sabino. Comentários à lei da escuta protegida: lei n.. 13.431 , de 4 de abril de 2017. 1.ed. - Florianópolis: Conceito Editorial, 2018. pg. 33.

MARIA, Ricardo Luiz de Bom; SILVA, Leda Pibernat da (colab). A Entrevista investigativa e o depoimento especial um projeto em construção unindo ciência, ética e legislação. Juizado de Violência Doméstica e Familiar contra a Mulher (JVDFM). Florianópolis, 2018.

MELLO, Celso Antônio Bandeira. Curso de Direito Administrativo, 27 edição, revista e atualizada até a Emenda Constitucional 64, de 4.2.2010. São Paulo: Malheiros Editores Ltda, $2010 . \quad$ p. $53 . \quad$ Disponível em <file:///D:/Downloads/Direito Administrativo - Celso Antonio B.pdf>.

PODER JUDICIÁRIO DO ESTADO DE SANTA CATARINA - CEIJ - Coordenadoria Estadual da Infância e Juventude - Relatório de Atividades 2018, Florianópolis. Dezembro de 2018. Disponível em <https://www.tjsc.jus.br>. Acesso em 10/03/19.

. TJSC - Depoimento Especial - Infância e Juventude, Florianópolis. 2019. Disponível em $<$ https://www.tjsc.jus.br/web/infancia-e-juventude/depoimentoespecial $>$. Acesso em 15/03/19.

- Resolução Conjunta GP/ CGJ n. 8 de 24 de setembro de 2018. Florianópolis. 2018. Disponível <https://www.tjsc.jus.br/legislacao/interna>. Acesso em 15/03/19.

POTTER, Luciane Bittencourt. Violência, vitimização e políticas de redução de danos. In: Potter, Luciane Bittencourt, Cezar Roberto (org.) Depoimento Sem Dano: por uma política criminal de redução de danos. Rio de Janeiro: Lumen Juris, 2010. 
Personalidade Acadêmica Homenageada:

Augustus B. Cochran III (Agnes Scott College)

A Vitimização secundária de crianças e adolescentes e a violência sexual infrafamiliar. Pontíficia Universidade Católica do Rio Grande do Sul. Dissertação de Mestrado. 2010. Disponível em $<$ https://www.dominiopublico.gov.br/download/teste/args/cp052863> .pdf. Acesso em $15 / 03 / 2009$.

SARLET, Ingo Wolfgang. A eficácia dos direitos fundamentais: Uma teoria geral dos direitos fundamentais na perspectiva constitucional. 11. ${ }^{\text {a }}$ ed. revista atual e ampl.. Porto Alegre: Livraria do Advogado Editora, 2012. <https://www.passeidireto.com/.../ebook---ingo-sarlet---a-eficacia-dos-direitos-fundam...> p. 128. Acesso dia 10/03/19.

PIOVESAN, Flávia: Proteção dos Direitos Sociais: Desafios do lus Commune SulAmericano. Rev. TST, Brasília, vol. 77, n. 4, out/dez 2011. p. 105. Disponível em $<$ https://juslaboris.tst.jus.br/bitstream/handle/20.500.12178/28340/004 piovesan.pdf? sequence $=5$ > . Acesso em 08/03/19. 